\title{
Willingness to Communicate and Second Language Speech Fluency: An Idiodynamic Investigation of Attractor States
}

\author{
Shahin Nematizadeh, Official Languages and Bilingualism Institute, University of Ottawa \\ iD https://orcid.org/0000-0002-3860-7719 \\ snematiz@uottawa.ca
}

\begin{abstract}
Willingness to communicate (WTC) has recently been researched as a dynamic variable, with some investigations viewing it as a complex dynamic system (CDS). One important property associated with CDS is the notion of attractor states, which are characterized by stable patterns of behavior. The present study employed an idiodynamic method to monitor per-second WTC changes with 20 participants during three-minute speaking tasks. Using idiodynamic graphs illustrating the WTC dynamics, patterns of stability were identified as the unit of analysis for WTC attractors. Temporal measures of the utterances that coincided with the WTC attractors were also examined. Results demonstrated that attractors were likely to emerge in both WTC and L2 fluency, and largely depended on two categories of content-related and linguistic-cognitive factors. Data analysis also indicates that WTC and L2 fluency exhibited parallel dynamics in most of the cases. The study's findings yield pedagogical implications that are discussed at the end.
\end{abstract}

Keywords: willingness to communicate, L2 speech fluency, complex dynamic systems (CDS), attractors, perturbations 


\section{INTRODUCTION}

Willingness to communicate (WTC) and L2 fluency have been viewed as complex dynamic systems (Nematizadeh \& Wood, 2021; Segalowitz, 2010); that is, they are composed of elements that interact and influence each other (LarsenFreeman \& Cameron, 2008). Interestingly, there are numerous factors that are thought to affect both of these variables, including lexical knowledge (Hilton, 2008; Nematizadeh \& Wood, 2019), lexical retrieval (Wood, 2016), self-perceived fluency (Nematizadeh, 2019), anxiety (MacIntyre \& Legatto, 2011; Pérez Castillejo, 2019), content and topic familiarity (Bui \& Huang, 2018; Cao \& Philip, 2006), and content planning (Bui \& Huang, 2018; Nematizadeh, 2019), just to name a few. Therefore, it is plausible to assume that WTC and L2 fluency may interact with each other in important ways. In support of this assumption, Segalowitz (2010), in his dynamicallyinformed provisional model of speech fluency, argued that an L2 speaker's motivation, including one's WTC, could shape their commitment to speak with optimal fluency at a given time, and this represents the theoretical framework of the present study.

WTC and L2 fluency have very rarely been investigated alongside each other. Apart from D'Amico's (2012) quantitative study investigating the impact of short-term study abroad versus at-home study contexts that found no correlation between the two variables, there have been three studies to date specifically investigating the interactions between these variables in real time (Nematizadeh \& Wood, 2019; Wood, 2012, 2016). While these studies have offered meaningful insights, the findings are limited due to the small number of participants and limited data. Further, none have discussed whether and how attractors-"'a process of stabilization" (Verspoor et al., 2008, p. 225)-emerge in WTC or fluency in speaking tasks.

Attractors, as important properties of CDS, are fairly under-researched in WTC and the L2 fluency literature, and the goal of the present study is to bridge this gap. To this end, this study adopted a CDS approach to investigate the dynamics of WTC attractors in real-time and in connection with accompanying temporal measures of L2 speech fluency.

\section{Complex Dynamic Systems and Individual Difference Variables}

The pioneering work of Larsen-Freeman (1997) applied complex dynamic systems theory (CDST) to the field of applied linguistics and the study of second language acquisition (SLA). Later, it was Dörnyei (2009) who called for viewing individual difference (ID) variables as CDS, arguing that the stable conceptualization of such variables was outdated and that CDST offered the possibility to explore the "situated and multicomponential nature of these higher order attributes" (p. 243). CDST holds that complexity, defined as "consisting of very many individual elements" (Thelen \& Smith, 1994, p. 51), emerges from the interaction between components of the system as well as the influence from external agents, thus making the system dynamic and nonlinear (Larsen-Freeman \& Cameron, 2008). CDS are also characterized by four properties that include: 1) sensitive dependence on initial conditions, how a small change can bring about bigger changes elsewhere in the system; 2) complete interconnectedness of subsystems, the interrelatedness between the constituent variables; 3) the emergence of attractor states, the preferred states a system settles into; and 4) variation both in and among individuals (de Bot et al., 2007).

A growing body of SLA studies has identified CDS characteristics in the investigation of IDs variables. In one of the first such studies on WTC, for instance, MacIntyre and Legatto (2011) observed rapid changes of WTC over time in several participants, some of which were attributed to affective, linguistic, and cognitive factors that were found to also affect each other, exemplifying the interconnectedness of subsystems. MacIntyre and Legatto also observed instances of attractors during which WTC tended to remain stable. In another study on the in-class motivation of four language learners, Waninge et al. (2014) observed considerable intra-individual variability in the participants' motivation levels. The researchers partly attributed this variability to contextual factors (e.g., class partners or the audience) or attitude, while some of the variability remained complex; that is, the researchers observed contradictory intra-individual results. The authors of this study also observed the property of dependence on initial conditions: two of the participants that started the lesson with high levels of motivation tended to maintain overall high motivation throughout the lesson despite some 
declines in motivation. Interestingly, the study also reported fairly similar group-level motivation dynamics, or what the authors called "strong attractors" (2014, p. 715), which they attributed to the class activities. In another dynamic study, Mercer (2015) employed, in part, an idiodynamic method to investigate the concept of the L2 self. She not only observed inter-learner variation, but also reported highly individual and idiosyncratic results for each participant. Some of the other literature exploring ID variables through a CDS includes works on WTC (MacIntyre, 2020; Wood, 2016), self-belief, self-concept, or possible-selves (Chan, 2014; Mercer, 2011 Nitta \& Baba, 2015), motivation (MacIntyre $\&$ Serroul, 2015; Waninge, 2015), anxiety and self-efficacy (Piniel \& Csizér, 2015), and foreign language enjoyment (Elahi Shirvan et al., 2020).

\section{Willingness to Communicate as a Complex Dynamic System}

As mentioned above, several empirical studies have investigated WTC as a CDS (e.g., Elahi Shirvan \& Taherian, 2016; MacIntyre \& Legato, 2011; Nematizadeh \& Wood, 2019; Peng, 2020; Syed \& Kuzborska, 2019; Wood, 2016) and some have observed the specific properties of WTC that characterize CDS (Kang, 2005; Mystkowska-Wiertelak, 2018; Mystkowska-Wiertelak \& Pawlak, 2014; Pawlak \& Mystkowska-Wiertelak, 2015; Pawlak et al., 2015). Despite this shift, very few studies provide explicit discussion of the notion of attractors on small timescales (e.g., MacIntyre \& Legato, 2011, Peng, 2020).

\section{Conceptualizing Willingness to Communicate Attractors}

There are times when a system settles into an attractor, defined as a "state the systems prefer to be in over other states at a particular point in time" (de Bot \& LarsenFreeman, 2011, p. 14). Attractors emerge as a result of the systems' self-organization that is triggered through internal interactions or the feedback the system receives from external forces (Hiver, 2015). Attractors are neither necessarily desirable nor permanent, and may be insensitive to small perturbations (van Geert, 2007)-conceptualized as a "disturbing force" (Hiver, 2015, p. 23). If strong enough, these perturbations may push the system out of an attractor.
As opposed to attractors, there are points in a developmental landscape that are not preferred by the system (de Bot et al., 2007) and these represent "unstable equilibria of the system" (Vallacher \& Nowak, 2009, p. 395). In these circumstances, in search of some stability, the system may self-organize into other possible attractors. A typical example of a system and its attractors is a ball rolling on a rather smooth surface like that of the moon with occasional holes and hills. While the ball is "attracted" to the holes (attractors), it is repelled by the hills (repellers). Once in a hole (attractor basin), it takes a lot of energy to move the ball out and begin rolling again. Repellers, on the other hand, are typically shorterlived and temporary (Thelen \& Smith, 1994).

In the context of L2 instruction, Hiver (2015) used the example of a group of second language (L2) learners as a CDS. The group begins a course with differing initial conditions and is influenced by several external (e.g., teacher, classmates, or context) and internal factors (e.g., L1 and L2 proficiency) throughout the course. However, after the learners collectively adapt to their respective roles and begin to formulate principles and norms to inform their classroom interactions and behaviors, some degree of stabilization is expected, and the system tends to transition into a more cohesive state-what could be referred to as an attractor state.

Regarding WTC, for instance, consistent provision of positive feedback by a teacher may lead to formation of an attractor of WTC among students, encouraging the use of a particular grammar structure. Any negative feedback from the teacher (external factor), or a minor cognitive lapse in lexical retrieval and formulating utterances (Wood, 2016) containing the structure (an internal factor) may affect students' WTC and discourage the use of the language structure. On the other hand, a teacher's frequent negative feedback on respective errors (an external factor) could trigger an attractor of avoidance to try out the structure in their language production due to fear of making errors. However, if a student is well prepared to use the structure (an internal factor), their WTC may temporarily rise, but the fear of using the structure and overall lack of WTC may also continue to exist as the dominant attractors. 


\section{Second Language Fluency as a Complex Dynamic System}

While the application of CDST has gained ground in the WTC literature, this is not the case with L2 fluency. However, there is some evidence that may help advance our understanding of the dynamicity of fluency. A comparative trait vs. state distinction similar to that of WTC (MacIntyre et al., 2009) has been put forward concerning fluency by Derwing et al. (2009) who distinguished between a trait view of fluency-that is, "a relatively permanent characteristic specific to an individual" (p. 534)-and a state view that is mainly perceived in terms of the differences in L1 and L2 fluency.

Additionally, Segalowitz (2010) adopted a CDS perspective and presented a cognitive view of fluency by identifying several CDS characteristics relatable to speech production, including dynamism and nonlinearity, interconnectedness, adaptation, and openness of the system. However, in this framing there is little that is explicitly connected to the concept of attractors except what Segalowitz calls "dynamic equilibrium" (2010, p. 18), which is realized through openness of the system to external sources. Notably, Segalowitz argued that speech production is a function of several underlying influences, including cognitive processes, social context, motivation to communicate, and perceptual and cognitive experiences, which cooperate to produce fluent speech. This view holds that motivation may "play a role in 'energizing' and shape the speaker's commitment to communicate with optimal fluency at a given moment and to decide whether to enter into a social context requiring L2 use" (2010, p. 22). This not only highlights the situation-dependent dimension of fluency, as is the case with WTC, but views motivation to communicate (e.g., WTC or socially grounded beliefs about communication) as a precursor to fluent speech. Segalowitz's view of speech fluency closely resembles the concept of attractors as being, according to Hiver (2015), an outcome of the interaction between internal elements (e.g., self-organization) as well as the effect of feedback received from external sources or contextual influences. Given the state view (Derwing et al., 2009) and the CDS view (Segalowitz, 2010) of L2 fluency, as well as the gap in the literature, it is important to investigate and gain insight into the dynamics of attractors in L2 speech fluency.
When viewed as a CDS, WTC and fluency may transition into states that exhibit rather stable, regular dynamics or undergo rapid, irregular changes. In either case, understanding these dynamics will not only contribute to this nascent body of literature, but will also carry implications for second language teachers wishing to have a better knowledge of the complex nature of L2 learners' performance and the underlying psycho-social factors. By adopting a dynamically-informed method, this study aims to identify instances of WTC attractors and compare their dynamics with those of co-occurring speech fluency.

\section{LITERATURE REVIEW}

Previous research has distinguished between a trait versus state view of WTC. While McCroskey and Baer (1985) assumed that L1 WTC was a "personality-based, trait-like predisposition" (p. 4), MacIntyre et al. (1998) conceptualized it "as a readiness to enter into discourse at a particular time with a specific person or persons, using a L2" (p. 547), implying that it is dynamic and context-dependent in nature. Recently, a growing number of studies have observed evidence of dynamicity in WTC (e.g., Cao, 2013; Cao \& Philp, 2006; Kang, 2005; Pawlak \& MystkowskaWiertelak, 2015). In a systematic review of the dynamic WTC literature, Nematizadeh \& Wood (2021) analyzed definitions of WTC and dynamically informed investigations of WTC, suggesting that WTC be viewed as a complex and dynamic variable. They further argued that there are a multitude of factors that underlie WTC which in turn make the decision to engage in L2 communication complex and dynamic.

\section{Willingness to Communicate Attractors}

Several CDS studies of WTC have observed the emergence of attractors in WTC. In pioneering the idiodynamic method, MacIntyre and Legatto (2011) had six participants complete eight consecutive speaking tasks on different topics, then self-rate their WTC changes moment-by-moment, and finally attend stimulated recall interviews (Gass \& Mackey, 2000) to explain the changes. Having observed many properties of CDS, the researchers observed that WTC attractors emerged as a participant felt confident and capable of doing the tasks. However, in the case of another 
participant, topic shifts perturbed the stability of WTC. In brief, the researchers observed attractors in participants' WTC when linguistic, social, cognitive, and emotional systems operated successfully to facilitate communication. However, failures in lexical retrieval also perturbed learners' WTC, causing at least one participant to abandon the task.

In a mixed-methods study of WTC changes, Pawlak and Mystkowska-Wiertelak (2015) engaged advanced learners of English in paired impromptu dialogues that lasted for less than 10 minutes. The participants were prompted using a beeping sound to self-rate their WTC every 30 seconds while performing the tasks; they also attended follow-up interviews and completed questionnaires. The researchers found that WTC was affected by a multitude of individual and contextual factors and this characterized the complex nature of CDS. They also observed stability in WTC when individuals expressed their opinions and views or were simply interested in the topics. The stability lasted as long as the speakers had ideas to carry on, exhibiting similar dynamics to an attractor.

In another idiodynamic study, Nematizadeh and Wood (2019) examined WTC changes in interaction with the temporal measures of fluency with four ESL learners. Having concluded, as other scholars did, that WTC exhibited properties of CDS, the researchers observed WTC attractors when one participant discussed their personal (daily) experience, while it dropped temporarily due to failure in lexical retrieval that perturbed their WTC.

Syed and Kuzborska (2019) adopted a CDS perspective to examine L2 WTC variations in postgraduate business students using structured classroom observations and stimulated recall interviews in a multiple case mixedmethods study. The researchers observed that one participant's motivation to become a successful communicator emerged as an attractor for WTC, despite perturbations as a result of the fear of his writing being criticized by the teacher. The researchers also reported that factors such as task, motivation, teacher, anxiety, selfconfidence and perceived opportunity to communicate collectively contributed to attractors in WTC. Another participant's WTC settled into an initial attractor due to the relevance of the topic but then shifted into a different attractor as her WTC dropped due to a number of negative factors (e.g., teacher and the classmates' attitudes). One of the participants also indicated that factors associated with class activities such as teacher-fronted interactional patterns, lack of teacher's attention, and lack of perceived opportunity to communicate affected her WTC, which the authors perceived as repellers.

In a more recent and relevant study, Peng (2020) employed a CDS perspective to investigate the interaction between classroom silence and WTC amongst four Chinese intermediate learners of English. Using observed behavior schemes, WTC self-ratings every five minutes, and stimulated recall, Peng identified five categories of attractors between silence and WTC, including 1) unwilling and silent, 2) capable but silent, 3) desirous but silent, 4) silent yet yearning, and 5) willing and breaking silence. The researcher also reported that a range of factors, including topical interest, linguistic and cognitive readiness, inadequacy, or difficulty (e.g., vocabulary knowledge), led the participants into certain WTC attractors.

The above studies' findings show that WTC attractors are likely to emerge and largely depend on contextual (e.g., topic or task), affective (e.g., anxiety, confidence, or motivation) and linguistic-cognitive (e.g., lexical retrieval, vocabulary knowledge, or perceived competence) factors, many of which have been found to also affect speech fluency.

\section{Second Language Speech Fluency}

The L2 fluency literature mainly regards fluency as speech fluidity (Segalowitz, 2010), rapidity, automaticity, flow, smoothness, or continuity of speech (Koponen \& Riggenbach, 2000), or as "naturalness of flow of speech" (Wood, 2010, p. 9). One relatively new perspective on fluency is the dichotomy of trait versus state fluency. The trait notion entails a "relatively permanent characteristic specific to an individual" (Derwing, et al., 2009, p. 534); however, the state conceptualization is largely subject to contextual factors (e.g., topic, interlocutor, setting) and may vary between first and second languages.

Arguably, the state notion shares the dynamic properties of CDS and therefore lends itself well to investigations of fluency as a CDS. Segalowitz's (2010) provisional framework of fluency also views it as a dynamic system. This framework demonstrates the dynamic relationship between four influences underlying L2 speech fluency, 
including cognitive and perceptual processing, motivation to communicate (e.g., WTC), social context, and the perceptual and cognitive experiences gained through engaging in communication and the social context.

Fluency is commonly measured using temporal features of speech such as speech rate, mean length of runs, pause quantity, and location (Kormos \& Dénes, 2004). These direct measures, which offer a more objective analysis, can be calculated manually or automatically using computer software like Praat (Boersma \& Weenink, 2020) and scripts written for this purpose (de Jong \& Wempe, 2009). Praat converts audio recordings into spectrograms that can be annotated to facilitate automatic or manual calculation of the temporal measures.

\section{Dynamic Investigations of WTC and L2 Fluency}

While the WTC literature provides some evidence concerning the notion of attractors, there is very little to learn about attractors in the fluency literature. For instance, the major focus of Segalowitz's (2010) dynamic framework was on other properties of CDS (e.g., non-linearity, openness, adaptation) and not on attractors per se. In an early study on WTC and fluency, Wood (2012) employed a longitudinal, repeated measures design to investigate the effect of perceived WTC of Japanese and Chinese students on their speech fluency gains through silent films retells. While he reported that the relationship between WTC and L2 speech fluency seemed nonlinear and complex, which is consistent with properties of CDST, the study was not framed within a CDS framework and did not discuss the concept of attractors. There are, however, two very relevant studies that looked at the per-second changes in fluency and WTC as a CDS. Wood (2016), who used an idiodynamic method, did not directly discuss attractors but concluded that WTC and L2 fluency were "linked and influence each other" (p. 25), suggesting that WTC and fluency interacted in certain ways. Wood also reported that when WTC was high, fluency was high and vice versa, giving the impression that stability in each could bring about stability in the other. In another idiodynamic study of WTC and fluency, Nematizadeh and Wood (2019) also observed very similar results regarding the parallel states of the variables at a given time-that is, most of the instances observed involved situations where high or low WTC co-occurred with fluent or dysfluent speech, respectively. The researchers attributed this to the interaction between linguistic, cognitive, and affective factors.

Given that WTC has been referred to as the final step leading to L2 use (MacIntyre et al., 1998), it is essential to understand the dynamics of WTC as speech is produced. Given the interaction between motivation to communicate and speech production in Segalowitz's (2010) framework, and the socio-cognitive bases of WTC and L2 fluency, it would be insightful to monitor these variables in real-time and explore the possible links that may emerge in the form of attractors. Therefore, the research questions this study aims to address are:

1. What factors are involved when WTC displays stable patterns of dynamics and what factors disrupt this stability?

2. What dynamics does L2 fluency exhibit during those periods of stability in WTC?

\section{METHOD}

\section{Participants}

As part of a larger project, twenty participants were recruited using a non-random purposive technique (Dörnyei, 2007; Mackey \& Gass, 2005). This is a non-probability sampling strategy that allows for selecting participants capable of communicating experiences and opinions in a reflective, expressive, and articulate manner (Bernard, 2006). Five inclusion criteria were used to ensure homogeneity of the data. The participants were between 25 and 35 years of age, spoke Farsi as their first language (L1), had resided in Canada for a period of 6 to 12 months. All participants were doing their graduate studies and had achieved an IELTS score of between 6 and 7 in the year prior to the study. Demographic details of 11 participants, whose WTC data exhibited attractors, are summarized in Table 1. 
Table 1. Participants' Profile

\begin{tabular}{cccclc}
\hline $\begin{array}{c}\text { Participants' } \\
\text { pseudonyms }\end{array}$ & Gender & $\begin{array}{c}\text { IELTS score } \\
(1-9)\end{array}$ & $\begin{array}{c}\text { Length of residence } \\
\text { (months) }\end{array}$ & Field of Study & Level of Study \\
\hline Niki & F & 7 & Approx. 12 & electrical eng. & PhD \\
Majid & M & 6.5 & Approx. 12 & technology innovation & Master's \\
Saba & F & 7 & Approx. 12 & mechanical eng. & PhD \\
Lili & F & 7 & 6 & chemical eng. & Master's \\
Sahra & F & 7 & Approx. 12 & computer science & Master's \\
Hero & M & 6.5 & Approx. 12 & computer science & Master's \\
William & M & 6.5 & 7 & technology innovation & Master's \\
Anita & F & 6.5 & 6 & sustainable energy & Master's \\
Soha & F & 7 & 6 & computer eng. & Master's \\
Mehrzad & M & 6 & 6.5 & electrical eng. & PhD \\
Kaami & M & 6.5 & Approx. 12 & system science & Master's \\
\hline
\end{tabular}

\section{Data Collection: Idiodynamic Method}

This study used an idiodynamic method (MacIntyre, 2012) to investigate the dynamics between WTC and L2 fluency. All participants attended four one-on-one sessions, in which they completed three-minute, mainly monologic, picturedescription tasks while being video-recorded. Prior to the data collection, the participants received a written introduction to the research in Persian and then read and signed the consent forms at the beginning of the first session. Each session, the participants were given a different topic accompanied by a set of relevant questions, images ${ }^{1}$, and vocabulary (Appendix). It was believed that this arrangement would facilitate the generation of supporting ideas and lexical retrieval, which have been found to affect WTC (MacIntyre \& Legato, 2011; Nematizadeh \& Wood, 2019; Wood, 2016). This was intended to allow for tracking down other potential factors that could influence WTC. During the interviews, the researcher kept eye-contact with the participants and engaged in communication whenever they required assistance, were uncertain how to continue, or asked questions.

Monologic tasks have been widely used in WTC research (MacIntyre et al., 1999; MacIntyre \& Legatto, 2011; Nematizadeh \& Wood, 2019; Wood, 2016). Additionally, picture description tasks, as the classic means of speech elicitation in fluency research (Segalowitz, 2010), allowed for the objective measurement of the temporal measures with little interference from the researcher. Having been video-recorded during the tasks, the participants viewed the recordings immediately after and, in a retrospective process, recalled their thought processes when performing the tasks and rated their WTC using the idiodynamic software (MacIntyre, 2012) on a scale between -5 (low WTC) and +5 (high WTC). The researcher screencaptured this phase as it was intended to facilitate the stimulated recall procedure. The idiodynamic application generated a bitmap graph illustrating WTC changes that partly helped with the stimulated recall. During the stimulated recall interviews, carried out in Farsi and also recorded, the researcher played the screen-captures of the WTC ratings and the participants explained the WTC changes. As for fluency, the video-recordings of the picture description tasks were later converted to audio for the measurement of the temporal features.

\section{Data Analysis}

\section{WTC Bitmap Graphs}

The main purpose of the present study was to monitor the emergence of attractors in WTC. Attractors were perceived 
as those patterns of behavior whereby WTC remained stable and displayed no irregular changes. Since the idiodynamic method captured per-second changes, the graphs reflecting an uninterrupted state lasting for more than a few seconds qualified as attractors. Therefore, consistently high or low ratings of WTC clearly suggested stability in the system and were perceived as attractors. In other cases, participants rated their WTC once and then reported no changes. Such cases were also perceived as stability in the system. On the other hand, any sudden shift of dynamics that was irregular compared to the preceding state and only lasted temporarily (e.g., a few seconds or less) was perceived as a perturbation. In the context of this study, such cases mostly involved patterns where consistently high WTC exhibited a sudden noticeable drop. Figure 1 illustrates a sample idiodynamic graph with the large colored rectangle representing a durable attractor and the smaller colored rectangles showing perturbations. As part of the larger study, a total of 80 bitmap graphs were generated from 20 participants. Eighteen graphs from 11 of the participants exhibited dynamics that corresponded to attractors and were thus analyzed in connection with the fluency dynamics of the cooccurring speech samples.

Figure 1. An Idiodynamic Graph Illustrating an Attractor and Subsequent Perturbations

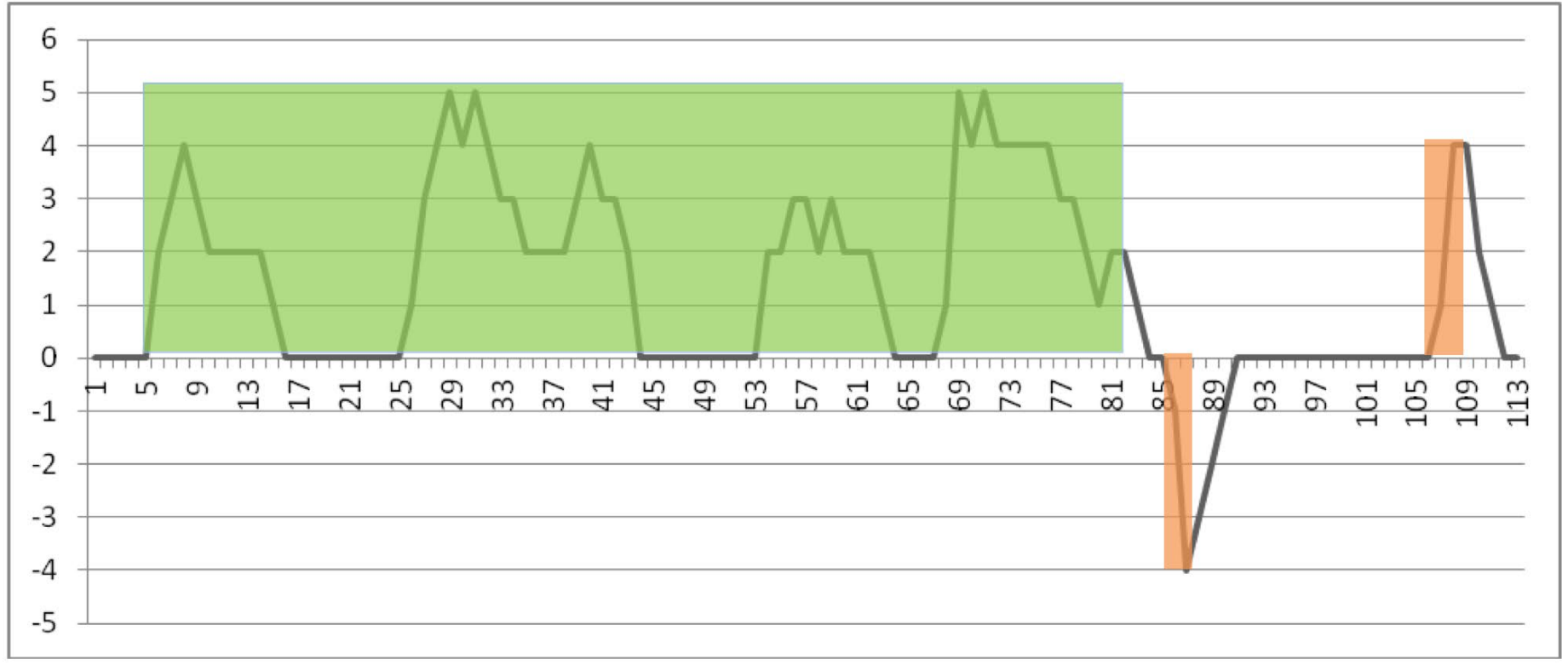

\section{Temporal Measures of L2 Speech}

The temporal measures of the L2 speech samples that coincided with the WTC attractors and perturbations were also analyzed to investigate interactions between speech fluency and WTC.

The speech samples were transcribed and manually annotated utterance by utterance in Praat (Boersma \& Weenink, 2020). Transcriptions were inserted into an online syllable counter (www.syllablecounter.net) to obtain the syllable counts, which were then divided by the total speech time in seconds to compute the speech rate (SR). Praat identified the length and number of pauses and spoken utterances, which were used to calculate the mean length of runs (MLR), i.e., the average number of syllables spoken per utterance/run. In this study, fluent L2 speech was characterized by runs whose syllables exceeded the MLR for each respective task, which is consistent with prior studies (Nematizadeh \& Wood, 2019).

The temporal measures of speech fluency, including SR, MLR, silent pauses, and filled pauses (FP) like 'um' or 'er', 
were used to inform the analysis of the speech co-occurring with WTC attractors and perturbations.

\section{Stimulated Recall Interviews}

Using NVivo, all the stimulated recall interviews were transcribed verbatim, translated into English, and coded in vivo (Saldaña, 2009). Factors leading to the attractors and perturbations were quantified to determine their frequency of occurrence. The emerging codes corresponding to the attractors and perturbations along with their preceding dynamics were analyzed to understand how the WTC dynamics emerged. Co-occurring dynamics of fluency, including the SR, MLR, and length and number of pauses in the speech samples, were also analyzed for any possible interaction with the WTC dynamics.

\section{RESULTS}

The results will be presented in two parts. First, the results of the qualitative coding of the stimulated recall interviews and the factors that emerged as contributors to WTC attractors will be outlined. Part two then presents the data of three patterns of WTC attractors that were observed in the bitmap graphs. Select scenarios of each attractor pattern illustrating the WTC dynamics will be presented along with the coinciding fluency dynamics including speech samples and their corresponding temporal measures of speech.

\section{Factors Leading to WTC Attractors or Perturbations}

The qualitative coding of the stimulated recalls produced seven categories of factors that triggered WTC attractors or perturbations. The WTC attractors and perturbations sometimes resulted from a single factor but, at others, multiple factors were at play. As Table 2 shows, possession of supporting ideas was the main factor (25) that brought stability and emerged as a WTC attractor. For most of the cases where WTC remained high for a while, the participants indicated that they felt secure in their speech as they possessed ideas and could carry out the tasks. On the other hand, lacking supporting ideas would very likely result in silence or pauses and perturb the high WTC out of its attractor. In one instance where William's WTC had settled into a long-lasting attractor because of possessing supporting ideas, his WTC suddenly dropped. To explain this, he stated: I lost WTC because I wished to provide further reasons why the quality of food at university food courts was not high, but not only did I lack reasons why, but also I did not feel confident about my own vocabulary knowledge.

Table 2. Factors Contributing to WTC Attractors and Perturbations

\begin{tabular}{|c|c|c|c|c|c|}
\hline & Factors & Factors leading to & Attractors & Perturbations & Total \\
\hline 1 & \multirow{4}{*}{ 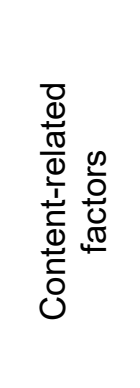 } & (Lack of) Supporting ideas & 15 & 10 & 25 \\
\hline 2 & & $\begin{array}{l}\text { Personal experience, belief, or interest, } \\
\text { opinion/view }\end{array}$ & 15 & 1 & 16 \\
\hline 3 & & $\begin{array}{l}\text { Topical knowledge (background knowledge, topic } \\
\text { familiarity) or prior communication experiences }\end{array}$ & 11 & 3 & 14 \\
\hline 4 & & Organizational (plan and preparedness) & 5 & 0 & 5 \\
\hline 5 & \multirow{3}{*}{ 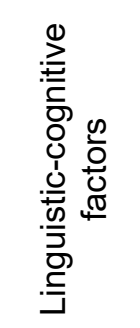 } & $\begin{array}{l}\text { Lexis-related (knowledge, search, or retrieval, } \\
\text { (in)appropriacy) }\end{array}$ & 9 & 10 & 19 \\
\hline 6 & & $\begin{array}{l}\text { Performance-related (pronunciation, irrelevant } \\
\text { speech, fluent speech, inaccuracies) }\end{array}$ & 4 & 5 & 9 \\
\hline 7 & & Cognitive load (structuring sentences) & 2 & 1 & 3 \\
\hline
\end{tabular}


The second category leading to attractors or perturbation involved lexis-related factors (19) including possession or lack of lexical knowledge, success or failure of lexical search and retrieval, and lexical appropriacy. In addition to the possession of supporting ideas, the participants required the lexical knowledge to maintain high WTC attractors, which was evident in William's comments in the previous paragraph. While William avoided the idea he wished to discuss in this particular example, in many other instances, the participants failed to retrieve appropriate vocabulary as they were talking. In one instance, Niki's high WTC was pushed out of an attractor as she failed to retrieve a lexical item and had to use another one. She stated: I did not recall the word I knew so I used another word and I was uncertain if it appropriately conveyed what I meant. This not only perturbed the attractor but also resulted in pauses in her speech. She added: I continued but remained preoccupied about it for a while, which might explain her declining WTC in the utterances that followed.

In situations where the participants lacked supporting ideas, they drew on personal interests, experiences, beliefs, or views, which comprised the third category of factors contributing to WTC attractors (16). For instance, after a series of perturbations due to hesitating about what to say, Kammi mentioned: I had attended online courses and this gave me a feeling of security to discuss its advantages. Recalling this personal experience improved and settled his WTC into a stable state, which lasted for a while. In the case of another high WTC attractor, Saba shared her personal belief regarding dieting, stating: my WTC was high as I was discussing my viewpoint on dieting. I personally believe people should not be on diet and should prevent a situation that would necessitate this as losing weight through diets is always a challenge not many people can overcome. Saba's WTC displayed no perturbations as she went over her personal belief.

The fourth category of factors that contributed to WTC attractors involved topical knowledge including background knowledge, topical familiarity, or prior communication experiences about a given topic (14). One of the instances occurred when Niki's WTC rose and remained stable for 85 seconds. She noted: I only recalled my background information about Persian food and a recent conversation I had in English with a friend over my father's blood sugar. However, when she introduced the topic of dieting, her WTC declined: I felt at a loss for supporting ideas because I had never been on a diet and thus was bereft of ideas. Both of these cases demonstrate how topical knowledge and prior experiences stabilized her WTC, which was subsequently perturbed due to a topic shift. There was another instance where William's declining and fluctuating WTC rose and gained stability as he turned to discuss a more familiar topic. He noted: I felt much more knowledgeable and confident to discuss Persian ethnic foods and my likes and dislikes than the quality of foods in universities' food courts. After this shift of topic, his WTC rose and remained high for a while.

WTC attractors and perturbations were also observed due to participants' self-perceived performance (8). Four of the instances involved cases where the participants' WTC remained stable as they felt impressed with their fluency, accuracy, or control over the task as they were talking. For instance, a high WTC attractor emerged as William perceived his speech as highly fluent. His WTC remained very stable and high throughout the task with no decline. He noted: I was willing because I was simply thinking and smoothly producing speech in English, and not translating from Persian. On the other hand, there were instances where the participants' disappointment with their performance, such as issues with grammar accuracy, uncertainty about pronunciation or coherence of ideas, perturbed their WTC. In Mehrzad's case, a high WTC attractor was perturbed as he mispronounced a word. He noted: my WTC rapidly declined because I noticed the mispronunciation of the word 'experienced,' but tried to ignore and continue to avoid pausing. He also added that he was simultaneously struggling with sentence construction.

The sixth category that triggered the high WTC attractors involved organizational factors, including participants' plans or preparedness for completing tasks (5). In most of the cases, this category pertained to the participants' ability to gather their thoughts, note them down, make an outline, and feel prepared to complete the task in the one-minute preparation time they were given prior to the speaking tasks. In cases where they ran out of ideas, they would take a quick look at their notes and manage to continue without a pause. At the outset of Task 1, William's WTC rose and remained stable for the better part of the task and he explained: I had a plan, the supporting ideas, and the appropriate vocabulary to 
complete the task. In another instance, Mehrzad's fluctuating WTC stabilized for a short period because he had developed a plan for that specific period. He stated: $I$ had decided to clarify that there is not one best type of education and what suits you best really depends on individuals, their major, and goals. This was the plan that had improved his WTC.

The seventh category related to cognitive capacity required for constructing sentences (3), which contributed to low WTC attractors or perturbation. In the three instances observed, Kaami, Mehrzad, and Majid stated that they felt unable to smoothly construct sentences and maintain the flow of speech. In one of the instances where Kaami's WTC remained low for a while and his speech was full of pauses, he said: I felt very frustrated with my performance because I had run out of ideas, so I had to improvise new supporting ideas and put them in words simultaneously. A low WTC attractor emerged during this period essentially because this was too much to handle and caused cognitive overload in sentence construction. The other two instances also involved very similar dynamics wherein Mehrzad and Majid had to improvise ideas and deal with online sentence construction, which imposed a high cognitive demand on them and perturbed their WTC.

\section{Patterns of the WTC Attractors and Corresponding Fluency}

As shown in Table 3, the identified cases were roughly categorized into three patterns exhibiting both attractors and/or perturbations. The first pattern involved the emergence of a single attractor. The second pattern pertained to the formation of an attractor followed by multiple subsequent perturbations. In the third pattern, WTC displayed and moved between attractors and perturbations. Analysis of the cases showed that speech fluency tended to exhibit similar dynamics to that of WTC in most of the cases. In other words, stable and high WTC mostly coincided with stable and fluent speech. Likewise, unstable and shifting WTC mostly coincided with unstable and dysfluent speech. In the following section, representative cases concerning each pattern will be presented and discussed.

\section{Pattern 1: A Single Attractor}

Soha - Task 2. In Soha's case, an attractor emerged as her WTC rose and remained stable for the entire task (see Figure 2). Her speech remained fluent (MLR 8.2 syl./run., SR $2.88 \mathrm{syl} . / \mathrm{sec}$.) compared to her fluency measures in the other three tasks (MLRs in T1: 7.08, T3: 7.56, T4: 7:99). Her WTC rose at the outset as she retrieved ideas and therefore felt capable of completing the task. This coincided with two fluent runs:

(Soha 1): "... on campus education is the best way to (12 Syl., +1) (Silent .80) to the education and there are (Silent .65) many reasons (FP .57) (Silent .52) (FP .45) generally I think that I believe that online education is not $(19$ Syl., +1)..."

Her WTC rose as she discussed her personal opinion in the first run, but she appeared to be struggling with how to carry on, which is evident from the three pauses. Immediately after, she generated an idea (on-campus programs only) that kept her willing to continue. This also coincided with the following cluster of fluent runs:

(Soha 2): “... long-term kind of education it's not (11 Syl. +1) (Silent .46) (FP .69) (Silent .80) possible in my mind to do that as a like a (13 Syl) (Silent .58) degree whole degree for a (Silent .57) complete course like university (9 Syl., +1) (Silent .50) (FP .40) it's just suitable for like one course program doing online or for ten for (19 Syl., +1) (Silent .51) (FP .31) a subjects that are just about reading and not something (15 Syl.)..."

Shortly after, her WTC rose because she retrieved additional supporting ideas (disadvantages of online courses) and she was able to add some humor to her talk, which gave her a feeling of control over the task. This coincided with another cluster of fluent runs:

(Soha 3): “... experiments and these things (+1) (Silent .68) or may maybe solving some problems (9 Syl.) (FP .44) it's not suitable for that kind of things (11 Syl.) (Silent .69) and because of this there are kind of like disadvantages of doing online courses and I believe that online courses (27 Syl., +2) (Silent .44) they are just (Silent .39) suitable more suitable to do some like cheating doing cheating (LF) and these things it's easier to do on 
an online course and the exams are like $(36 \mathrm{Syl} .,+3)$ ...”

Towards the end, her WTC remained high as she discussed a personal experience involving an online course she had taken in her previous job, which she also managed to do fluently:

(Soha 4): “... to be honest if I just wanna have a degree I prefer online course but if I want to learn something it's better to (33 Syl., +1) (Silent .35) have a on campus course (Silent .47) and I have tried like I say that because I have tried both of them (16 Syl., +1) ..."

As can be seen, a combination of factors contributed to the formation of the WTC attractor throughout the task. Her fluency also never underwent any major perturbations and she effortlessly maintained fluent speech.

Table 3. Identified Cases of Attractors and Perturbations

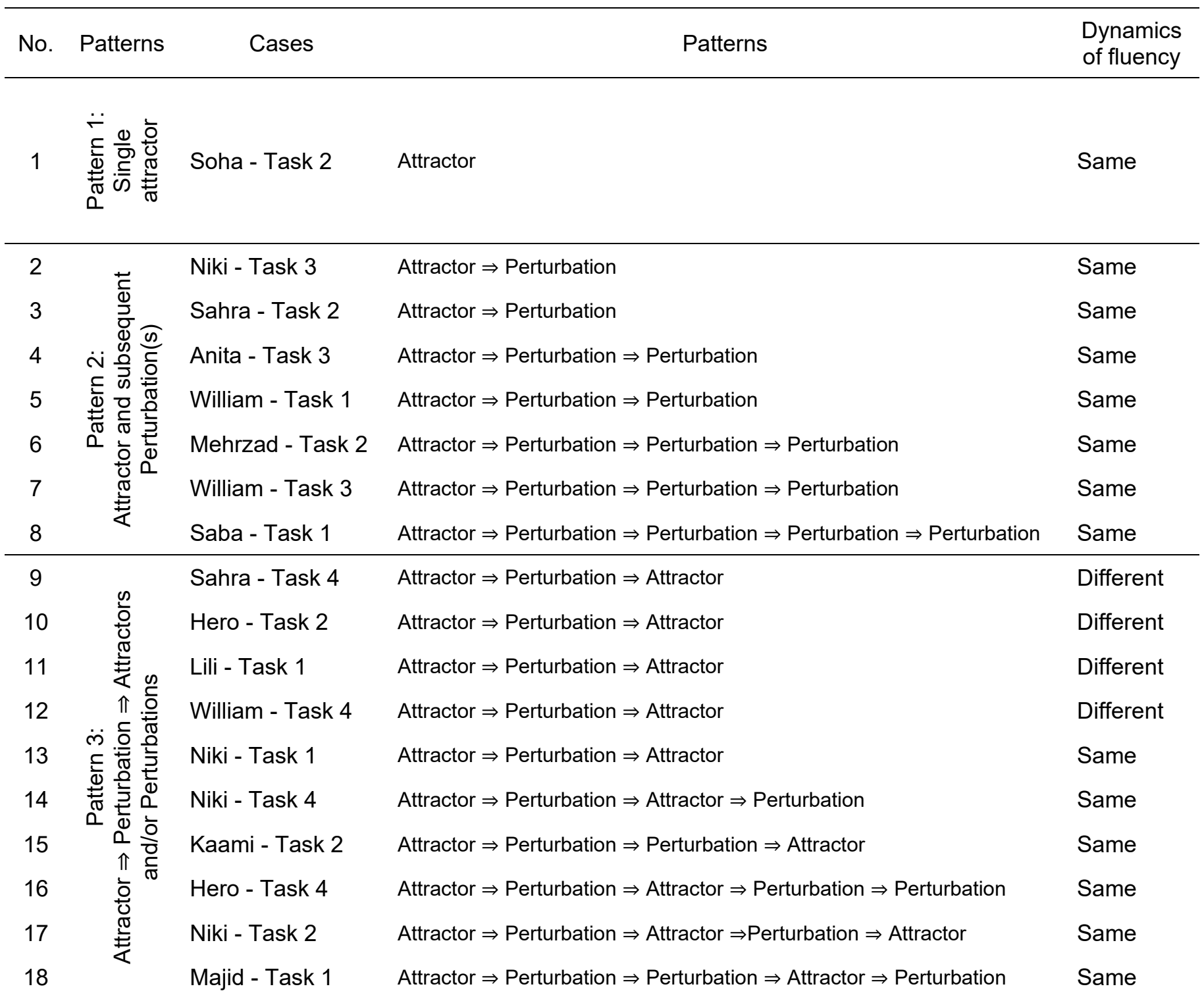

Note. "Same" corresponds to instances where WTC and fluency exhibited the same dynamics and "different" refers to instances where the variables displayed different dynamics. 
Figure 2. Soha's WTC Attractor

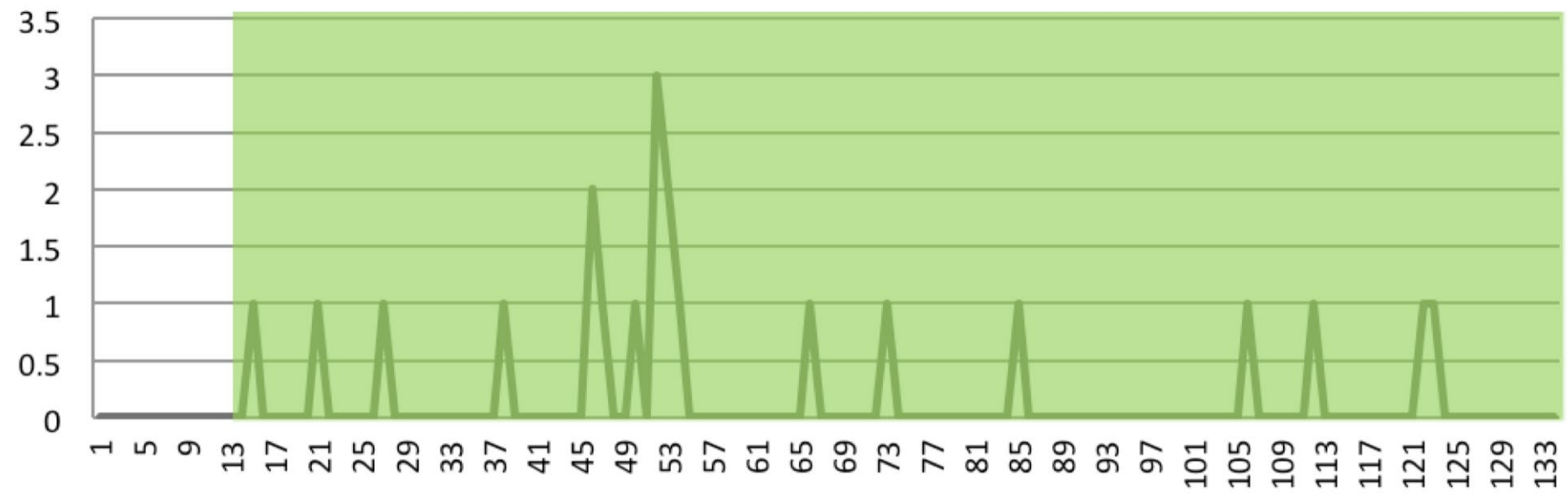

\section{Pattern 2: Attractor and Subsequent Perturbation(s)}

Seven of the cases involved WTC settling into an attractor followed by perturbations.

Sahra - Task 2. Sahra's mainly high WTC dropped after a long-lasting attractor (Figure 3) due to lexical retrieval failure. Factors triggering the attractor included background knowledge, relevant lexical items, and discussing personal preferences and interests, all collectively helping her with content and linguistic resources that kept her willing to continue. Failure in lexical retrieval perturbed the attractor and simultaneously resulted in a multiple consecutive pauses:

(Sahra 1): “... I can't say which is exactly is more efficient in a specific field of study (Silent .74) (FP .71) but (Silent .34) I (FP .70) (Silent .51) nowadays (Silent .42) were going to ours this (FP .89) (FP.76) (-4) (Silent 2.29) (FP.56)

(Silent 1.43) (Silent 1.22..."

Interviewer: this trend?

(Sahra 1): “...(FP .68) maybe (Silent .37) this point of view that (FP .44) online education is better..."

Anita - Task 3. Anita's WTC entered a long-lasting attractor (Figure 4) as she discussed her personal interests, used supporting ideas, and accessed relevant vocabulary owing to her relevant educational background. Towards the end of the attractor, she drew on her personal experience to discuss a disadvantage of technology. The following cluster contained four fluent runs with a SR of $2.92 \mathrm{syl} . / \mathrm{sec}$. that is higher than her overall SR of 2.76 syl./sec., despite the consecutive pauses towards the end:

(Anita 1): “... but it also has some disadvantages for example when (15 Syl.) (FP .65) (Silent .38) your data will be lost (Silent .55) or as a one time it happened to me (10 Syl., +2) (Silent .44) (FP .63) like three years or two years ago (Silent .26) my cell phone was stolen (Silent .44) and I was just like (Silent .27) (Silent .39) I lost (Silent .27) (FP .48) (Silent .42) (FP .56) (Silent .28) really wide range of my life. I lost everything I didn't have access to any of them I haven't backup (29 Syl., +3) ..."

A few runs later, however, running out of supporting ideas perturbed her WTC. She regretted not elaborating and going through her notes too quickly, which left her with no more to say. Despite the fluent run towards the end, there were frequent pauses and the SR for the following cluster was $2.73 \mathrm{syl} . / \mathrm{sec}$., which was lower than her overall task SR, showing that her fluency was simultaneously influenced:

(Anita 2): “... those datas again (Silent 1.34) and (FP .52) about (FP .56) other (FP .92) (Silent .71) when for example (FP.33) even (FP.81) when I am using (FP .34) the (-1) my cell phone or the computer (Silent .69) I I use (FP .34) I try to use (Silent .28) even all the thing I did it manually by them (13 Syl.) (Silent .38) such as for example (.85) (Silent .43) for example when I want to study something (13 Syl., -1) ..." 
Figure 3. Sahra's WTC Attractor and Perturbation

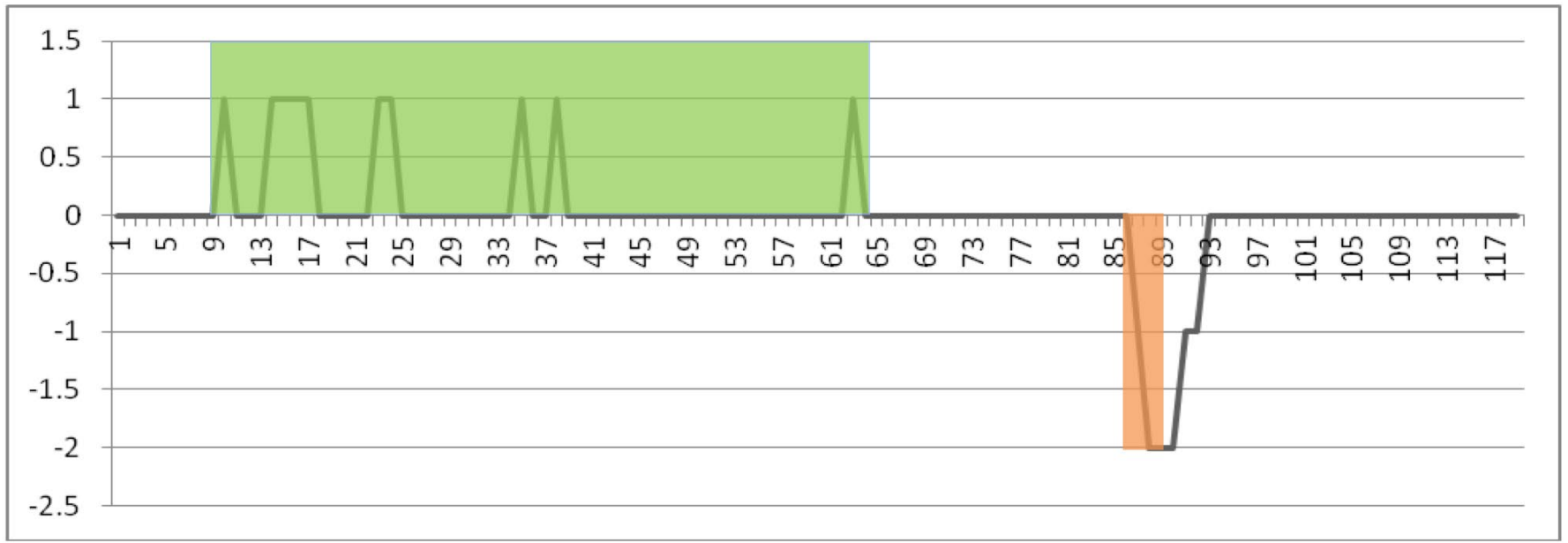

Figure 4. Anita's WTC Attractor and Perturbation

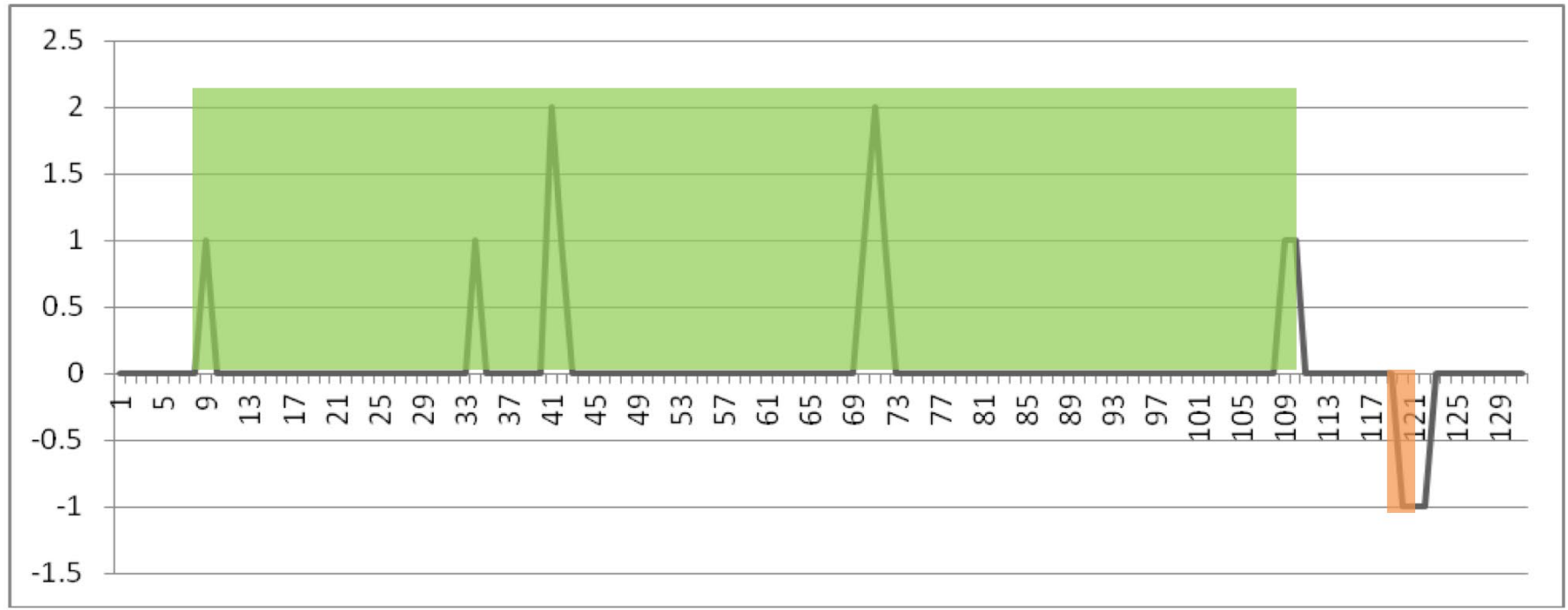

Figure 5. Saba's WTC Attractor and Perturbation

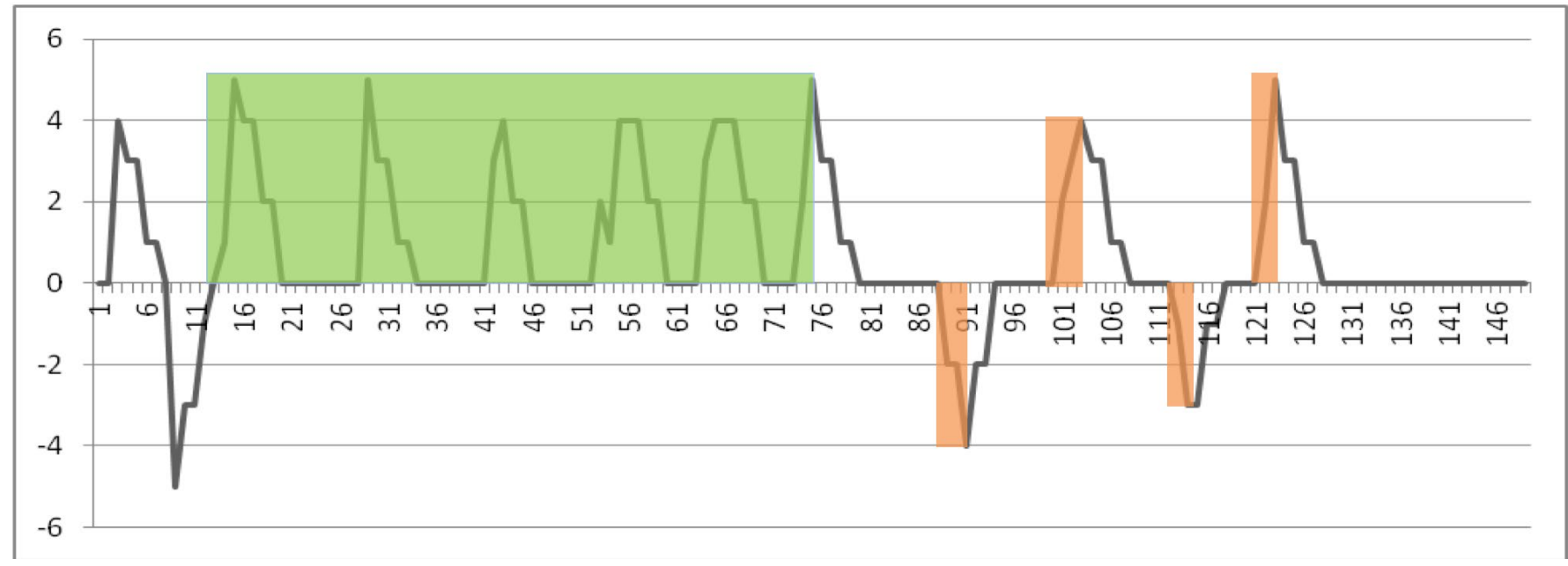


Saba - Task 1. Saba's WTC initially entered into an attractor followed by a series of consecutive perturbations (Figure 5). Factors contributing to the attractor included discussing her personal beliefs, possessing supporting ideas, and feeling prepared to elaborate further. The attractor began in the middle of the task while she was discussing her personal belief (avoiding diets). The co-occurring speech is also fluent:

(Saba 1): “... so much weight because I know that it's gonna be really difficult and tough to lose the weight (24 Syl., +5) (Silent .55) so I just try to control my weight instead of (Silent.41) eating a lot of food and then (Silent .40) trying to be on a diet to lose the weight (Silent .32) so I just try to control what I am eating what I am drinking however it's really difficult because sometimes you cannot avoid you know eating sweet things because I really love $(49$ Syl., +5) ..."

Later, however, running out of ideas seemed to perturb the high WTC attractor as well as her fluency. She explained that in a conversation, other interlocutors would contribute to the talk, while here, she was the only one in charge of keeping the talk going. Multiple pauses dominated due to a lack of ideas, making her uncomfortable and unwilling to continue the task:

(Saba 2): “... not to gain a lot of weight (Silent .75) (FP .65) other thing that (Silent .33) I can say about healthy food (-4) (Silent .46) (FP .45) (Silent .32) I think eating fruit fruits and vegetables ..."

Towards the end of the task, her WTC was perturbed several times due to failure in lexical retrieval. Struggling to retrieve lexical items for some snacks lowered her WTC, which rose again as she formulated an idea and managed to produce more fluent speech. However, immediately after, failing to retrieve lexical items about unhealthy snacks resulted in a series of pauses and repetitions of "to". This perturbed her WTC and fluency:

(Saba 3): “... fruits in your bag and then whenever you feel that you are hungry you can just have it as a snack like banana like apple (31 Syl., +5) (Silent .27) I think they are really good and (FP .67) also they are really healthy (Silent .40) so (Silent .67) I think it's good just (FP .29) try to (Silent 1.17) to (Silent .47) (FP .67)(Silent .25) to avoid eating like snacks (Silent .34) they have (-4) a lot of like sugars a lot of ..."

Pattern 3: Attractor $\Rightarrow$ Perturbations $\Rightarrow$ Attractors and/or Perturbations

This pattern involved back-and-forth transitions of WTC between attractors and perturbations with six of 10 cases starting with a WTC attractor that was subsequently perturbed, but then settled into a second attractor. The remaining four cases began with an attractor and proceeded with either perturbations or attractors.

Lili - Task 1. At the outset, Lili's WTC rose and entered an attractor (Figure 6) that coincided with a few fluent runs as she discussed her interests and beliefs:

(Lili 1): "I want to talk with you about my food habits and my (14 Syl., +3) (FP .52)(Silent .75) diets to tell about my diets and (8 Syl., +1) (Silent .26) at first I want to mention that (12 Syl., +5) (Silent .54) I'm (Silent .28) so conscious about my diet I mean I'm (12 Syl.) ..."

She mentioned that she was very interested to discuss her likes about food so she had ideas and was prepared to discuss them. Later, the attractor persisted as she recalled a personal experience (of gaining weight):

(Lili 2): “... I had a sedentary lifestyle (11 Syl., +4) and (FP .52)(Silent 1.02) didn't do any (FP.56)(Silent .80) sports (FP.44)(Silent 1.09) any sports okay? (Silent .40) (FP .43) so on the time I decided to lose my weight and have a $(14$ Syl., +1) ..."

She added that retrieving the collocation "sedentary lifestyle" had also improved her WTC. Later, despite a series of pauses due to struggling to retrieve "any sport" the WTC attractor did not diminish. She decided to just leave it there and go back to reviewing her experience, which she liked to share with the interviewer. Subsequently, in the following clusters of fairly consecutive fluent runs, the attractor lingered on as she formulated the idea of food pyramids in the first cluster below:

(Lili 3): “... food pyramid I mean I eat carbohydrates and I eat vegetables and I eat (22 
Syl., +5) (Silent .39) fruit (Silent .62) and (FP .60) everything in a food pyramid in a day $(13 \mathrm{Syl} .,+3)$ (Silent .44) I try to be (Silent .31) to have a healthy diet and healthy lifestyle (13 Syl., +2) ..." (Lili 4) “... fast food because sometimes I need. Sometimes I need to eat unhealthy sometimes I say to my husband (28 Syl., +3) (FP .38) we need (Silent .61) (FP .69) some micro micro organism and some bacteria and some unhealthy eating (20 Syl., +3) ..."

Prior conversation experiences about healthy and unhealthy eating habits had improved her WTC in the second cluster. After the long-lasting attractor, her WTC was eventually perturbed due to lack of supporting ideas. While the first run was fluent, her WTC was perturbed as she was concerned as to what to say next, leading to fragmented speech and a series of consecutive pauses:

(Lili 5): “... I can't avoid them and totally omit them from my life (Silent 1.5, -2) and (Silent .66) about (FP .78) (Silent .93) different type of (Silent .36) different type of (FP .59) foods (Silent .46) ..."

The drop in WTC was temporary and a few runs later, she gained WTC again as she discussed a personal interest. Discussing her personal interest coupled with retrieving the words "well-done" and "rare" settled her WTC into an attractor that lasted till the end of the task:

(Lili 6): “... I'm into (FP .55) sea foods but (Silent .77) (FP .41) well done sea foods not rare sea food and (9 Syl., +5) (Silent .42) I'm so interested about vegetables and fruits (14 Syl., +3) (Silent .32) (FP. 59) if there is a dinner table if (9 Syl.,) (Silent .73) here is a dinner table I prefer to eat vegetables and fruits rather than meats and (23 Syl., +5)..."

Majid - Task 1. Majid's WTC settled into a series of attractors and repellers in task one (Figure 7). His WTC was slightly perturbed due to the slow lexical retrieval (healthy diet), causing three pauses. However, both WTC and fluency immediately moved into an attractor for almost the entire cluster as he retrieved relevant ideas and appropriate words:
(Majid 1): “Ok. let's now talk about our food our (FP .41) any (-1) (Silent .44)(FP .55) healthy diet we have or not (+3) (Silent .45) so (FP .60) at first I wanna to I wanna talk about myself because I really I really like $(23 \mathrm{Syl} .,+5)$ I really like to (Silent .44) eat a lot and especially when there is delicious food (16 Syl., +2) (Silent .38) whenever my when my wife (Silent .34) cooks (+5) (Silent .48) for me but (FP .35) in terms of talking about diet I have never been on diet (15 Syl., +1) but (Silent .61)(FP .58) sometimes I choose to stop eating some specific things like coke like sugar (19 Syl., +3) (Silent .57)(FP .57) these kinds of things I always like to drink these kinds of things (14 Syl., +3) (Silent .94) it depends..."

A few utterances later, another perturbation came about due to the slow retrieval of the word "jam", failure to retrieve further vocabulary related to the context (e.g., other breakfast meals), and uncertainty about the pronunciation of the word "artificial". His fluent speech also turned dysfluent:

(Majid 2): “... improve our diet or way of eating every day for example for breakfast we are choosing foods and you know natural things in terms of instead of (Syl. 38) (Silent .70)(FP .49)(Silent .28) jam or (-4) (Silent .28) you know (Silent .74) anything has any artificial flavor (-5) in it (Silent .52) ...”

Immediately after, he regained WTC upon recalling further supporting ideas, which facilitated fluent speech. Subsequently, however, his WTC significantly dropped due to lack of supporting ideas and having to improvise to avoid pausing. Speaking impromptu was a challenge to him as he struggled with smoothly planning and structuring sentences and retrieving ideas, settling his WTC into a long low WTC attractor from the middle to the end of the following cluster, during which his speech became relatively dysfluent, characterized by frequent pauses and shorter than normal runs:

(Majid 3): “...in it (Silent .52) but it (Silent .26) it depends on the situation sometimes we're gathering together we are you know we are in party we are not choosing whatever we are eating (40 Syl., +2) (Silent .28) I cannot (Silent .26) prevent myself to touch that so I am going to pick that one (15 Syl.) 
(Silent .26) yeah (Silent .26) but (FP .55) in our home when we are choosing whatever we are gonna eat yeah we choose (19 Syl. +1)(FP .43) the healthier one (Silent .66) (FP .35) (-5) (Silent 2.08) (FP 1.11) (Silent 2.65) (-5) most of the time because we are from a country (silent .27) who know (Silent .28) (-5) the people in my country (-7) cook different kind of foods we are using meat (-2) we are using (Silent .58) (FP .33) (Silent .33) different (Silent .58) you know we are using (-5) (Silent .74) herbs we are ee. different kinds of (-4) (Silent .42) foods (-4) (FP. 54)(Silent .39) I cannot say I am in specific kind of food but sometimes (Silent .33) can say (Silent .29) I do not (Silent .36) eat (Silent .66) specific seafood (Silent .47) but (FP 1.07) I eat for example I can say I do not eat ham or pork but (Silent .49) you know (Silent .76) (FP .48) so (FP .48) (Silent 1.53) what else (-2) (Silent .50)(FP 1.42)(Silent .47) ..."

Figure 6. Lili's WTC Attractor and Perturbation

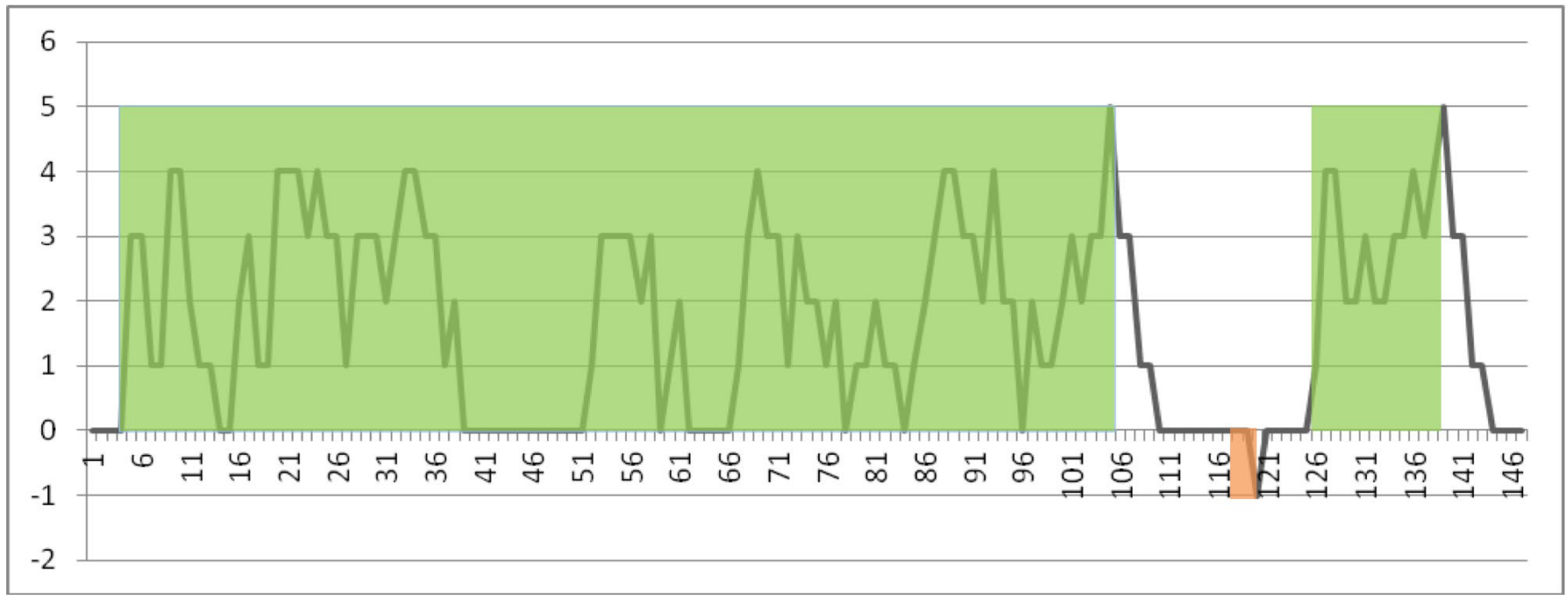

Figure 7. Majid's WTC Attractor and Perturbation

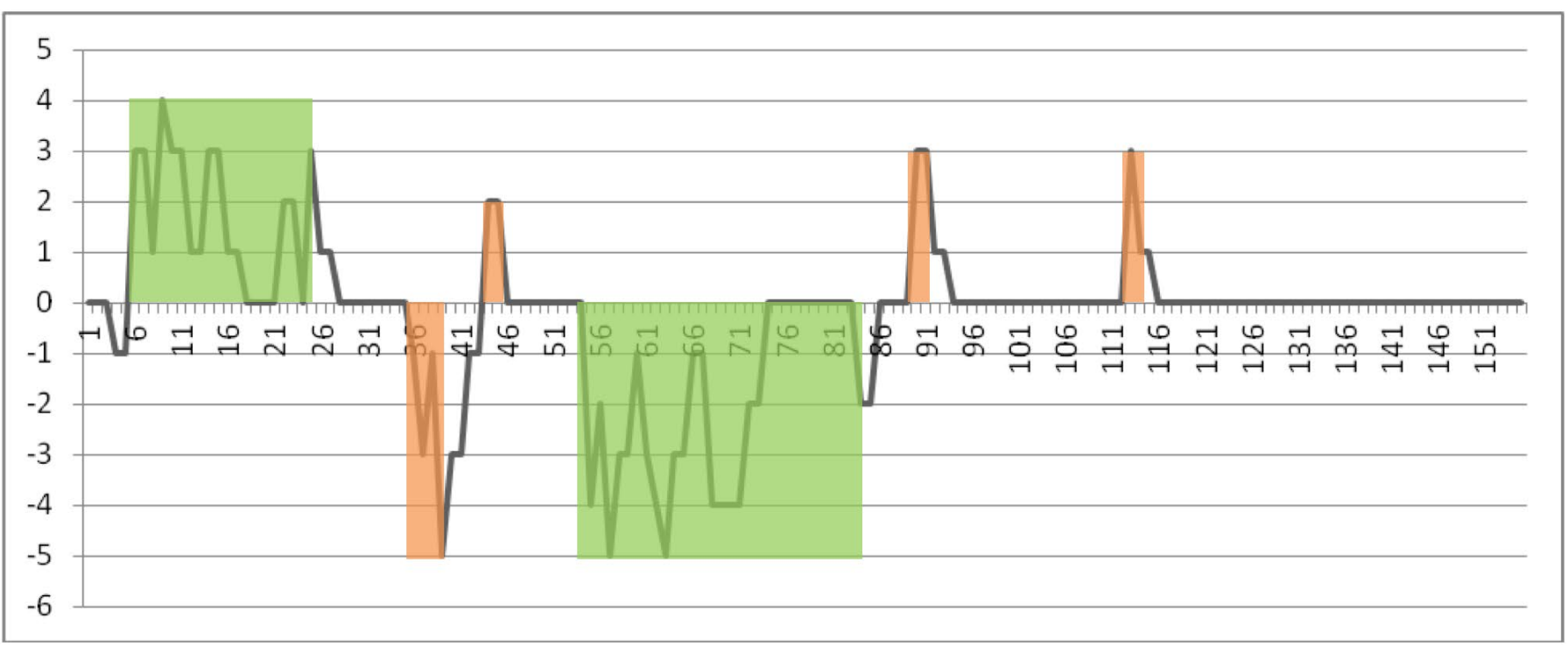




\section{DISCUSSION}

The analysis of 18 idiodynamic graphs exhibiting WTC attractors and perturbations led to two important issues concerning WTC and fluency. First, most of the attractors observed in this study involved cases where WTC rose and remained high for a period ranging from several seconds to over a minute. There were very few cases where low WTC attractors were observed, which might be due to the limited amount of data. However, perturbations to the WTC system involved irregular and short-lived rises or drops in WTC levels. Second, speech fluency appeared to exhibit parallel dynamics to those of WTC in most of the cases. The following section will address the two research questions and present an overall discussion of the findings.

\section{Research Question 1}

The first question aimed to uncover the factors that shape or perturb WTC attractors. Overall, the factors that triggered stability or change in the dynamics of WTC fall into two broad categories: 1) content-related factors including possession of supporting ideas or topical knowledge, discussion of personal experiences, interests, and views or beliefs, and organizational factors like content planning and preparedness; 2) linguistic-cognitive factors including lexis-related factors, self-perceived performance, and sentence-construction. Interestingly, both categories affected WTC and L2 fluency directly or indirectly.

\section{Content-related Factors}

High WTC attractors emerged mainly because the participants were able to recall and/or formulate ideas for discussion, which is consistent with previous research (Kang, 2015; Mystkowska-Wiertelak \& Pawlak, 2014; Pawlak \& Mystkowska-Wiertelak, 2015; Wood, 2016). The data demonstrate that participants were primarily concerned with content-or 'what to say'-and almost all of them indicated that possessing ideas improved their WTC. It appeared that supporting ideas raised their confidence to express themselves and dispelled the fear of falling silent for the duration of the tasks. In case of lacking ideas, the participants creatively linked their personal experiences, interests, or views and beliefs to the discussion of the tasks and generated ideas, which is also consistent with previous research (Kang, 2005; Pawlak et al., 2015). Alternatively, some of the participants' WTC rose because they possessed background knowledge (e.g., field of study) or had prior conversations about a topic, both of which tie in well with previous studies (Cao, 2011; Cao \& Philp, 2006; Nematizadeh \& Wood, 2019). These prior communicative experiences very likely served as opportunities to practice or try out certain grammar structures and appropriate lexical resources, which would not only boost their WTC to use these features in the interviews but also help them do it more fluently. However, there were quite a few cases wherein a high WTC attractor was temporarily perturbed and entered a low WTC state (repeller) merely due to the fact that the participants ran out of ideas. In a word, the content-related factors facilitated high WTC attractors largely because the participants did not struggle to formulate ideas. In such cases, they remained exclusively focused on form and fluency including recall or retrieval of appropriate structures and/or lexical items.

\section{Linguistic-cognitive Factors}

While the emergence of WTC attractors was primarily triggered by content-related factors, their subsequent stability and continuity appeared to largely depend on the participants' linguistic knowledge (lexical knowledge for the most part) and how effectively they managed to execute the cognitive processing and retrievals. The main factor that contributed to WTC in this category involved lexis-related factors such as lexical knowledge and retrieval, which mirror previous research (MacIntyre \& Legatto, 2011; Nematizadeh \& Wood, 2019; Wood, 2016). In fact, another important factor that improved the participants' WTC to approach a topic was whether they possessed the required vocabulary knowledge. For instance, Anita mentioned that her rich vocabulary about the topic of technology had given her a feeling of security that contributed to a long-lasting WTC attractor. On the other hand, William's high WTC attractor was perturbed as he lacked the vocabulary to make his point. He, therefore, switched the topic to discuss a more familiar topic and was then able to stabilize his WTC. This instance resembled a system's self-organization into a stable state, whereby William exhibited agency in deliberately turning to discuss a topic he felt more confident about.

In addition to lexical knowledge, high WTC attractors also depended on on-going, successful lexical retrieval. Smooth lexical retrieval facilitated and lengthened the WTC attractor, which would otherwise be perturbed. In fact, 
failure in lexical retrieval was the second factor that led to WTC declines. Additionally, lexical retrieval failure coupled with the cognitive demand of online sentence structuring increased the cognitive load, perturbing both WTC and L2 fluency. One last factor affecting WTC attractors was the participants' self-perceived performance. WTC was perturbed in some cases when participants selfmonitored their speech quality and detected mispronunciations, lexical inappropriacy, grammatical inaccuracy, or irrelevant supporting ideas. All in all, these linguistic-cognitive factors contributed to the continuity of attractors or perturbations in WTC.

\section{Research Question 2}

The second question aimed to monitor the dynamics of speech fluency during WTC attractors and perturbations. Findings show that L2 fluency also settled into states that not only closely corresponded to WTC dynamics, but also were, in most cases, parallel to those of WTC. One explanation for this is that both WTC and L2 fluency were simultaneously affected by the two categories of contentrelated and linguistic-cognitive factors. A glitch in any of these variables was likely to affect both WTC and fluency. For instance, possessing supporting ideas not only improved the participants' WTC to carry on the tasks but also facilitated fluent speech. As long as the ideas came naturally, the participants managed to convert them into speech and the WTC and fluency attractors continued to last. On the other hand, lack of ideas led to silence or pauses, which not only created uncomfortable moments that perturbed WTC but also characterized dysfluent speech. In fact, struggling to recall or formulate supporting ideas while remaining silent created a cognitive load as a result of simultaneously preparing a content message and converting it into speech. This lowered WTC temporarily and, in most cases, resulted in dysfluent speech.

While WTC and L2 fluency exhibited co-occurring dynamics in most of the cases, a few cases did not follow this pattern. In one case, while Hero managed to build three consecutive fluent runs, his WTC dropped as he perceived his ideas irrelevant and incoherent while still managing to keep fluent speech. It is worth noting that this lack of confidence in his argument finally led to a number of connected pauses. A very similar scenario occurred in Lili's case as her WTC attractor was perturbed while her speech turned dysfluent slightly later (Lili 5). It appeared that a lack of supporting ideas had lowered her WTC slightly before it manifested through her speech fluency. The two exceptions may suggest a slight time lapse between affect (WTC changes) and performance (speech production). In the third case, William managed to maintain fluency throughout task four but lost WTC temporarily due to perceiving the supporting ideas irrelevant. While he seemed to hesitate here, he managed to ignore and move on fluently. Lastly, Sahra's WTC rose and entered an attractor while her fluency dropped. She was reminiscing about a group of Francophones who had admired her French language skills; therefore, she felt proud of herself and willing to discuss it despite doing this dysfluently.

\section{Willingness to Communicate and L2 Fluency Attractors}

Given that in most of the cases, WTC and fluency exhibited similar dynamics concerning the formation of attractors or perturbations, it is plausible to argue that these two variables may somehow interact as speech is produced. In fact, there were many instances wherein a lowered WTC coincided with frequent pauses or, in a few cases, the participants lost WTC due to self-perceived dysfluency. Therefore, as long as the two variables operated smoothly, attractors emerged and persisted in both, while abrupt glitches in one variable resulted in perturbations in the other. Emergence of WTC attractors or perturbations largely depended on the two categories of factors which were simultaneously facilitating fluent L2 speech production. Smooth interactions between content-related and linguistic-cognitive factors created attractors that exhibited stability in WTC and fluency. However, temporary malfunctions like lack of supporting ideas or failure in lexical retrieval moved the WTC and fluency systems towards less stability and greater perturbations. Such states turned to attractors if the speakers continued to struggle. In the case of Majid, simultaneous content planning and sentence structuring challenges led to WTC perturbations that lasted for approximately 15 seconds (Majid 3). Likewise, his speech gradually lost quality and turned dysfluent. In this case, the content-related and linguistic-cognitive factors served as subsystems of both WTC and fluency wherein both factors triggered a decline in his WTC as he struggled to formulate ideas and smoothly convert them into speech. Overall, in the context of attractors, the two categories of factors discussed above 
served as subsystems that underlie WTC and fluency and are likely to interact and influence each other.

\section{CONCLUSION}

The present study took an unprecedented step in uncovering the emergence of attractors in WTC and L2 fluency. Using the idiodynamic method that allowed for the analysis of WTC graphs and qualitative coding of stimulated recalls, two categories of content-related and linguistic-cognitive factors were found as contributors to WTC and fluency dynamics. Further analysis of WTC and fluency dynamics showed that the variables entered into parallel attractors and exhibited similar perturbations in most of the cases. This could be explained by the fact that factors shaping the dynamics of speech production could simultaneously affect WTC.

The present study offers implications for L2 teachers, particularly the two categories of content-related and linguistic-cognitive factors. This study found evidence that WTC attractors were formed or perturbed when the participants possessed or lacked content knowledge (what to say), respectively. To generate ideas, they sometimes recalled relevant personal experiences, interests, or views and beliefs. Also, topical knowledge and prior conversation experiences emerged as factors that contributed to WTC attractors. Therefore, L2 teachers are encouraged to take these factors into account when developing lesson plans or during class activities. Learners with low WTC should constantly be presented with meaningful opportunities to express themselves, and this happens if they find the topics relevant and can bring their personal experiences, interests, views and beliefs to class discussions. The more such opportunities are presented, the more likely the learners are to be engaged, paving the way for WTC attractors. Additionally, teachers are advised to proactively provide exposure and rehearsals of lexical resources and grammar structures that learners will require to complete classroom tasks. This would not only improve WTC but would also increase the cognitive capacity for smoother recalls and retrievals and reduce cognitive demands, thereby contributing to fluency attractors.

This study comes with some limitations. First, the study used laboratory-based data (e.g., monologic tasks) and this may have limited the scope of the findings. In an ideal world, researchers are encouraged to collect authentic data and observe communications in real-life settings. Future studies are encouraged to use dialogic or authentic communicative events to collect more ecologically valid data. Given that attractors may also emerge as a result of external feedback (Hiver, 2015), using authentic tasks with several participants will most likely yield deeper insights into the WTC attractors. Also, the results presented are based on 18 out of a total of 80 bitmap graphs that came from 11 out of 20 participants with specific demographics. Given these limitations, interpretations should be made with caution, as the field's knowledge of such dynamics is still nascent. Since this was one first attempt to specifically look at attractors, the study identified cases with long enough dynamics that clearly corresponded to attractors; therefore, the results may have excluded cases where shorter attractors emerged. Additionally, the data were collected from participants with specific nationality, age, proficiency level, and similar length of exposure to L2 English; therefore, these findings are likely to be most applicable to populations with similar demographics. There is, therefore, a need to extend and substantiate this study with different demographics of participants. Lastly, the idiodynamic method provides evidence of moment-by-moment changes in variables; however, it would be illuminating to conduct studies over longer timescales (e.g., hours, weeks, months) in order to gain a better picture of the attributes and processes that contribute to the formation of WTC and L2 fluency attractors.

\footnotetext{
${ }^{1}$ Images used in all tasks were retrieved from https://www.shutterstock.com/ but were not included in the present manuscript due to copyright.
}

\section{Acknowledgements}

I would like to express my gratitude to Dr. David Wood, Dr. Phil Hiver, and the two anonymous reviewers for their constructive feedback on the earlier drafts of this paper. 


\section{Author's Contributions}

Shahin Nematizadeh wrote this manuscript based on his doctoral dissertation. He carried out all the phases of the project, including developing the study design, receiving ethics clearance, collecting and analyzing data, and writing the drafts. He read and approved the final draft.

\section{Ethics Approval \& Consent to Participate}

This study was approved by the Carleton University Research Ethics Board (approval no. 107238). All participants signed written informed consent prior to enrollment and data collection in the study.

\section{Funding}

This project received no funding.

\section{Notes on the author}

Dr. Shahin Nematizadeh is an L2 teacher trainer, and teaches applied linguistics and English courses in Ottawa, Canada. His research interests center around the psychology of language learning, L2 teacher education and student engagement, and L2 speech fluency. $\mathrm{He}$ also investigates individual difference variables through a complex dynamic systems perspective.

\section{REFERENCES}

Bernard, H. R. (2006). Research methods in anthropology: Qualitative and quantitative approaches. AltaMira Press.

Boersma, P., \& Weenink, D. (2020). Praat: doing phonetics by computer [Computer program]. Version 6.1.10, retrieved 23 March 2020 from http://www.praat.org/

Bui, G., \& Huang, Z. (2018). L2 fluency as influenced by content familiarity and planning: Performance, measurement, and pedagogy. Language Teaching Research, 22(1), 94-114. https://doi.org/10.1177/1362168816656650

Cao, Y. (2011). Investigating situational willingness to communicate within second language classrooms from an ecological perspective. System, 39(4), 468-479.

https://doi.org/10.1016/j.system.2011.10.016

Cao, Y., \& Philp, J. (2006). Interactional context and willingness to communicate: A comparison of behavior in whole class, group and dyadic interaction. System, 34, 480-493. https://doi.org/10.1016/j.system.2006.05.002

Chan, H. Y. L. (2014). Investigating L2 motivation amongst EFL secondary school students in Hong
Kong using dynamic systems theory. [Unpublished doctoral dissertation]. University of Nottingham.

de Bot, K., \& Larsen-Freeman, D. (2011). Researching second language development from a dynamic systems theory perspective. In W. Lowie, K. de Bot, \& M. Verspoor (Eds.), A dynamic approach to second language development: Methods and techniques (pp. 5-23). John Benjamins.

de Bot, K., Lowie, W., \& Verspoor, M. H. (2007). A dynamic systems theory approach to second language acquisition. Bilingualism: Language and Cognition, 10(1), 7-21.

\section{https://doi.org/10.1017/S1366728906002732}

De Jong, N. H., \& Wempe, T. (2009). Praat script to detect syllable nuclei and measure speech rate automatically. Behavior Research Methods, 41(2), 385-390. https://doi.org/10.3758/BRM.41.2.385

Derwing, T. M., Munro, M., Thomson, R. I., \& Rossiter, M. (2009). The relationship between L1 fluency and L2 fluency development. Studies in Second Language Acquisition, 31(1), 533-557. https://doi.org/10.1017/S0272263109990015

Dörnyei, Z. (2007). Research methods in applied linguistics. Oxford University Press. 
Dörnyei, Z. (2009). Individual differences: Interplay of learner characteristics and learning environment. Language Learning, 59, 230-248. https://doi.org/10.1111/j.1467-9922.2009.00542.x

Elahi Shirvan, M., \& Taherian, T. (2016). Dynamic emergent patterns of L2 willingness to communicate within the ecology of the classroom. Konin Language Studies, 4(4), 415-438.

Elahi Shirvan, M., Taherian, T., \& Yazdanmehr, E. (2020). The dynamics of foreign language enjoyment: An ecological momentary assessment. Frontiers in Psychology, 11, 1391-1391.

https://doi.org/10.3389/fpsyg.2020.01391

Gass, S. M., \& Mackey, A. (2000). Second language acquisition research. Stimulated recall methodology in second language research. Lawrence Erlbaum.

Hilton, H. (2008) The link between vocabulary knowledge and spoken L2 fluency. The Language Learning Journal, 36(2), 153-166. https://doi.org/10.1080/09571730802389983

Hiver, P. (2015). Attractor states. In Z. Dörnyei, P.D. MacIntyre, \& A. Henry (Eds.), Motivational dynamics in language learning (pp. 20-28). Multilingual Matters.

Kang, S. J. (2005). Dynamic emergence of situational willingness to communicate in a second language. System, 33(2), 277-292. https://doi:10.1016/j.system.2004.10.004

Koponen, M., \& Riggenbach, H. (2000). Overview: Varying perspectives on fluency. In $\mathrm{H}$. Riggenbach (Ed.), Perspectives on fluency (pp. 524). University of Michigan Press.

Kormos, J., \& Dénes, M. (2004). Exploring measures and perceptions of fluency in the speech of second language learners. System, 32(2), 145-164. https://doi.org/10.1016/j.system.2004.01.001

Larsen-Freeman, D., \& Cameron, L. (2008). Research methodology on language development from a complex systems perspective. The Modern Language Journal, 92(2), 200-213. https://doi:10.1111/j.1540-4781.2008.00714.x
MacIntyre, P. D. (2012). The idiodynamic method: A closer look at the dynamics of communication traits. Communication Research Reports, 29(4), 364-576.

https://doi.org/10.1080/08824096.2012.723274

MacIntyre, P. D. (2020). Expanding the theoretical base for the dynamics of willingness to communicate. Studies in Second Language Learning and Teaching, 10(1), 111-131. https://doi.org/10.14746/ssllt.2020.10.1.6

MacIntyre, P. D., Babin, P. A., \& Clément, R. (1999). Willingness to communicate: Antecedents and consequences. Communication Quarterly, 47(2), 215-229.

https://doi.org/10.1080/01463379909370135

MacIntyre, P. D., Dörnyei, Z., Clément, R., \& Noels, K. A. (1998). Conceptualizing willingness to communicate in a L2: A situational model of L2 confidence and affiliation. The Modern Language Journal, 82(4), 545-562. https://doi.org/10.2307/330224

MacIntyre, P. D., \& Legatto, J. J. (2011). A dynamic system approach to willingness to communicate: Developing an idiodynamic method to capture rapidly changing affect. Applied Linguistics, 32(2), 149-171. https://doi.org/10.1093/applin/amq037

Mackey, A., \& Gass, S. M., (2005). Second language research: Methodology and design. Lawrence Erlbaum.

McCroskey, J. C., \& Baer, J. E. (1985). Willingness to communicate: The construct and its measurement. Paper presented at the annual meeting of the Speech Communication Association, Denver, CO. (ERIC Document Reproduction Service No. ED265604)

Mercer, S. (2011). Language learner self-concept: Complexity, continuity and change. System, 39(3), 335-346. https://doi.org/10.1016/j.system.2011.07.006

Mercer, S. (2015). Dynamics of the self: A multilevel nested systems approach. In Z. Dörnyei, P.D. MacIntyre, \& A. Henry (Eds.), Motivational 
dynamics in language learning (pp. 139-163). Multilingual Matters.

Nematizadeh, S. (2019). Willingness to communicate and second language speech fluency: A complex dynamic systems perspective. [Unpublished doctoral dissertation]. Carleton University.

Nematizadeh, S., \& Wood. D. (2019). Willingness to communicate and L2 speech fluency: An investigation of affective and cognitive dynamics. The Canadian Modern Language Review, 73(3), 197-215. https://doi.org/10.3138/cmlr.2017-0146

Nematizadeh, S., \& Wood, D. (2021). Second language willingness to communicate as a complex dynamic system. In N. Zarrinabadi \& M. Pawlak (Eds.), New perspectives on willingness to communicate in a second language (pp. 7-23). Springer.

Pawlak, M., \& Mystkowska-Wiertelak, A. (2015). Investigating the dynamic nature of L2 willingness to communicate. System, 50, 1-9. https://doi.org/10.1016/j.system.2015.02.001

Pawlak, M., Mystkowska-Wiertelak, A., \& Bielak, J. (2015). Investigating the nature of classroom willingness to communicate (WTC): A micro-perspective. Language Teaching Research, 20(5), 654-671.

https://doi.org/10.1177/1362168815609615

Peng, J. E. (2020). Willing silence and silent willingness to communicate (WTC) in the Chinese EFL classroom: A dynamic systems perspective. In J. King \& S. Harumi (Eds.), East Asian perspectives on silence in English language education (pp. 143-165). Multilingual Matters.

Pérez Castillejo, S. (2019). The role of foreign language anxiety on L2 utterance fluency during a final exam. Journal of the Academy of Marketing Science, 36(3), 70-86. https://doi.org/10.1177/03079459994335

Piniel, K., \& Csizér, K. (2015). Changes in motivation, anxiety and self-efficacy during the course of an academic writing seminar. In Z. Dörnyei, P.D. MacIntyre, \& A. Henry (Eds.), Motivational dynamics in language learning (pp. 164-194). Multilingual Matters.

Saldaña, J. (2016). The coding manual for qualitative researchers (3rd ed.). SAGE.

Segalowitz, N. (2010). Cognitive bases of second language fluency. Routledge.

Syed. H., \& Kuzborska, I. (2019). Understanding the nature of variations in postgraduate learners' willingness to communicate in English. Cogent Education, 6(1). https://doi.org/10.1080/2331186X.2019.1606487

Thelen, E., \& Smith, L. B. (1994). A dynamic systems approach to the development of cognition and action. MIT Press.

Vallacher, R. R., \& Nowak, A. (2009). The dynamics of human experience: Fundamentals of dynamical social psychology. In S.J. Guastello, M. Koopmans, \& D. Pincus (Eds.), Chaos and complexity in psychology: The theory of nonlinear dynamical systems (p. 370-401). Cambridge University Press.

van Geert, P. (2007). Dynamic systems in second language learning: Some general methodological reflections. Bilingualism: Language and Cognition, 10(1), 47-49. https://doi.org/10.1017/S136672890600280X

Verspoor, M., Lowie, W., \& van Dijk, M. (2008). Variability in second language development from a dynamic systems perspective. The Modern Language Journal, 92(2), 214-231. https://doi.org/10.1111/j.1540-4781.2008.00715.x

Waninge, F., Dörnyei, Z., \& de Bot, K. (2014). Motivational dynamics in language learning: Change, stability, and context. The Modern Language Journal, 98(3), 704-723. https://doi.org/10.1111/modl.12118

Waninge, F. (2015). Motivation, emotion and cognition: attractor states in the classroom. In Z. Dörnyei, P.D. MacIntyre, \& A. Henry (Eds.), Motivational dynamics in language learning (pp. 195-213). Multilingual Matters. 
Wood, D. (2010). Formulaic language and second language speech fluency: Background, evidence, and classroom applications. Continuum.

Wood. D. (2012). Willingness to communicate and L2 fluency: complexity and variety in a corpus of
Japanese and Chinese ESL learner speech. Contact Magazine, 38(2), 23-39.

Wood, D. (2016). Willingness to communicate and second language speech fluency: An idiodynamic investigation. System, 60, 11-28. https://doi.org/10.1016/j.system.2016.05.003

\section{APPENDIX}

\section{Food and Healthy Eating}

1) Do you think you eat healthy? What are healthy and junk foods? Why?

2) Do you care about what you eat or do you avoid certain foods?

3) Are you or have you ever been on a diet? Why? Is it dangerous?

- Eating healthy/nutritious junk foods

- Counting calories

- To be or to go on a diet

- To lose/gain weight

- To watch what one eats

- Meat/seafood/vegetables/fruits

- Protein/Carbohydrates

- Delicious/tasty

- Organic vs. Genetically modified foods

- Food Pyramid 